\title{
PROCESSOS DE GESTÃO EM MICROEMPRESAS RURAIS: ESTUDO MULTICASOS
}

\section{MANAGEMENT PROCESSES IN RURAL MICROENTERPRISES: A MULTICASE STUDY}

\author{
Liamara Scalon \\ Bacharel em Administração pela Universidade Federal da Fronteira Sul-UFFS \\ Chapecó, SC, Brasil \\ Email: liascalon@hotmail.com \\ Fabrício Simplício Maia \\ Professor do curso de Administração da Universidade Federal da Fronteira Sul - UFFS \\ Chapecó, SC, Brasil \\ Email: fabricio.maia@uffs.edu.br \\ Tatiane Silva Tavares Maia \\ Professora do curso de Administração da Universidade Federal da Fronteira Sul - UFFS \\ Chapecó, SC, Brasil \\ Email: tatiane.maia@uffs.edu.br
}

\section{RESUMO}

O presente estudo tem por objetivo analisar e discutir as características dos processos de gestão das equipes de direção de microempresas rurais em uma cidade de pequeno porte na região oeste catarinense. Para tanto, utilizou-se como base o modelo teórico proposto por Filion (1999b), o qual focaliza o processo gerencial dos empreendedores. $O$ método de pesquisa adotado foi o estudo multicasos, de cunho qualitativo-descritivo. Os casos foram construídos por meio de entrevistas semiestruturadas com oito equipes de direção das empresas rurais pesquisadas. Os resultados desse estudo indicaram que, com base no modelo de Filion (1999b), as oito equipes de direção investigadas possuem características empreendedoras. Demonstrando que os agricultores familiares possuem condições de serem empreendedores no seu setor. Conclui-se, portanto, que uma gestão eficiente de suas propriedades possibilita que os microempresários rurais se tornem competitivos e sustentáveis nesse segmento tão importante a economia.

Palavras-chave: Empreendedorismo. Microempresas Rurais. Processos de Gestão. Agricultura Familiar. Equipes de Direção.

\section{ABSTRACT}

The present study has the objective of analyzing and discussing the characteristics of management processes of rural microenterprise management teams in a small city in the western region of Santa Catarina. For that, the theoretical model proposed by Filion (1999b), which focuses on the managerial process of the entrepreneurs, was used as base. The research method adopted was the multicase study, with a qualitative-descriptive character. The cases were constructed through semi-structured interviews with eight management teams of the rural companies surveyed. The results of this study indicated that, based on the model of Filion (1999b), the eight management teams investigated have entrepreneurial characteristics. Demonstrating that family farmers are able to be entrepreneurs in their sector. It is concluded, therefore, that an efficient management of its properties allows the rural micro-entrepreneurs to become competitive and sustainable in this segment so important in the economy.

Keywords: Entrepreneurship. Rural Microenterprises. Management Processes. Family farming. Teams of Direction.

Data de aprovação: 24 de outubro de 2018. 


\section{INTRODUÇÃO}

Nesse estudo apresenta-se uma pesquisa sobre o empreendedorismo relacionado ao meio rural, enfatizando o processo gerencial das equipes de direção de microempresas rurais em uma cidade de pequeno porte, no Estado de Santa Catarina. Afinal, faz-se necessário que o gestor rural, ao administrar sua propriedade, desenvolva os preceitos do empreendedorismo como estratégia para seu desenvolvimento e aperfeiçoamento. Essa nova forma de agir conduzirá ao melhor aproveitamento dos recursos disponíveis (LIMA; PARTELI; LOOSE, 2015), conferindo maior eficiência aos processos produtivos e oportunizando melhorias nos resultados.

Em virtude da necessidade de incentivar o empreendedorismo como ferramenta para o desenvolvimento econômico e social, de maneira especial, aos microempresários rurais, faz-se necessário o desenvolvimento de instrumentos que identifiquem as características dos processos de gestão empreendedor. Diante disso, surgiu a problemática de pesquisa, que reside na compreensão e discussão dos processos de gestão das equipes de direção de microempresas rurais em uma cidade de pequeno porte. Para tal, empregou-se o modelo de atividades do processo gerencial de empreendedores de Filion (1999b).

Esse artigo comporta, além da presente introdução, a revisão bibliográfica em que se apoia o estudo, com discussão teórica sobre o empreendedorismo, modelo de atividades gerenciais de empreendedores, proposto por Filion (1999b), bem como uma abordagem ao agronegócio, com ênfase a importância da agricultura familiar para esse segmento. Em seguida, apresenta-se uma descrição dos procedimentos metodológicos utilizados na coleta e análise dos dados, depois são apresentados os resultados bem como suas análises. Finalmente, são tecidas as considerações finais.

\section{REFERENCIAL TEÓRICO}

\section{Empreendedorismo: conceitos e concepções}

A primeira concepção clara da função empreendedora ocorreu no século XVII, na França, na pessoa de Richard Cantillon. Para Filion (1999a, p.6), os manuscritos de Cantillon (1755 apud Filion, 1999a) "revelam um homem em busca de oportunidades de negócios, preocupado com o gerenciamento inteligente de negócios e obtenção de rendimentos otimizados para o capital investido". Seus manuscritos foram publicados após a sua morte, tornando-o o primeiro autor a demonstrar interesse pelos empreendedores. Onde, a gênese do pensamento sobre empreendedorismo está associada a diferentes concepções, as quais registra três visões principais acerca da expansão do fenômeno: a escola dos economistas, a dos behavioristas (comportamentalistas) e a dos percursores da teoria dos traços de personalidade ou ciências do comportamento.

Na busca da melhor definição para empreendedorismo, Dornelas (2012, p.28) o define como sendo o "envolvimento de pessoas e processos que, em conjunto, levam à transformação de ideias em oportunidades. E a perfeita implementação destas oportunidades leva à criação de negócios de sucesso". 
Dornelas (2012, p. 29) enfatiza ainda que "empreendedor é aquele que detecta uma oportunidade e cria um negócio para capitalizar sobre ela, assumindo riscos calculados". De modo complementar, Filion (1999a, p.19) define empreendedor como "uma pessoa criativa, marcada pela capacidade de estabelecer e atingir objetivos e que mantém alto nível de consciência do ambiente em que vive, usando-a para detectar oportunidades de negócios". O empreendedor vê a mudança como normal e como sendo sadia. Geralmente, ele não provoca a mudança por si mesmo. Mas, e isto define o empreendedor e o empreendimento, o "empreendedor sempre está buscando a mudança, reage a ela e a explora como sendo uma oportunidade" (DRUCKER, 2012, p.36).

Para Dornelas (2012, p.24), algumas características dos empreendedores de sucesso referem-se a: são visionários, sabem tomar decisões, são indivíduos que fazem a diferença, sabem explorar ao máximo as oportunidades, são determinados e dinâmicos, dedicados, otimistas e apaixonados pelo que fazem, independentes e constroem o próprio destino, ficam ricos, líderes e formadores de equipes, bem relacionados e organizados, planejam, possuem conhecimento, assumem riscos calculados e criam valor para a sociedade.

No que tange ao tema empreendedorismo relacionado ao meio rural, Lima (2010) salienta que os termos "empreendedorismo rural" e "empreendedor rural" são muito pouco explorados na literatura mundial. Depara-se basicamente com programas destinados a esse público, casos bem-sucedidos de empreendedores rurais, preocupações em relação ao futuro do jovem empreendedor rural, entre outros (LIMA, 2010, p.36).

Nesse sentido, cada vez mais o meio rural brasileiro, que conserva a tradução escravista e a percepção de que "[...] permanecer no meio rural associa-se a uma espécie de incapacidade pessoal de trilhar o suposto caminho do sucesso" (MIYAZAKI, 2008), demanda a adoção de uma nova visão, a qual requer constante preocupação com as mudanças econômicas nacionais e internacionais, com o objetivo de acompanhar e evoluir com tais mudanças, mas, para isso é necessário a organização dos processos administrativos internos às propriedades. Faz-se necessário ao produtor rural desenvolver uma visão administrativa especializada com enfoque gerencial para organizar e administrar o seu sistema de produção (KIYOTA, 1999).

Sob essa óptica, Lima, Parteli e Loose (2015) destacam que "os agricultores familiares necessitam trabalhar o empreendedorismo como estratégias para desenvolver suas propriedades", de modo a potencializar os recursos disponíveis, a fim de criar novos produtos e serviços ou aperfeiçoar os que já estão sendo comercializados.

Frente ao discorrido, evidencia-se que o tema empreendedorismo associado ao meio rural assume fundamental relevância, devido à importância de os agricultores adotarem estratégias de gestão em seus empreendimentos, com vistas a melhorar a produtividade e alcançar a sustentabilidade da propriedade.

Com a finalidade de ressaltar as particularidades e especificidades do processo gerencial de empreendedores, em comparação a outro grupo de gerentes-proprietários de pequenos negócios, os operadores, Filion (1999b) desenvolve um modelo de atividades gerenciais de empreendedores (Figura 1). 
Figura 1- O processo gerencial dos empreendedores.

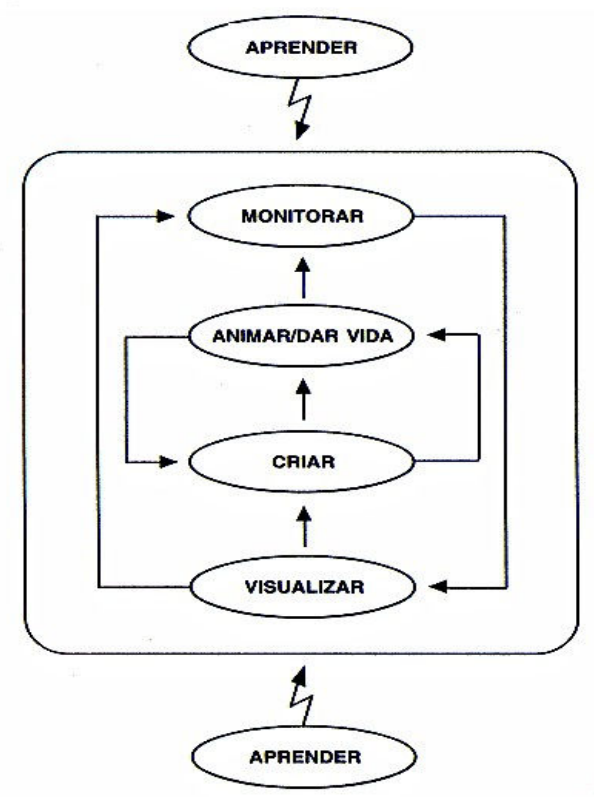

Fonte: Filion (1999b).

Esse modelo focaliza uma integração entre cinco elementos, abordando ainda fatores específicos compostos por cada elemento, conforme ilustrado no Quadro 1.

Quadro 1- Atividades do processo gerencial dos empreendedores.

\begin{tabular}{|c|l|}
\hline Principais elementos & \multicolumn{1}{|c|}{ Elementos componentes } \\
\hline Visualizar & $\begin{array}{l}\text { Contempla a identificação de um interesse em um setor de negócios, entender esse } \\
\text { setor, detectar uma oportunidade de negócios, imaginar e definir um contexto } \\
\text { organizacional e planejar. }\end{array}$ \\
\hline $\begin{array}{c}\text { Criar uma arquitetura de } \\
\text { negócios }\end{array}$ & $\begin{array}{l}\text { Implica a formulação de visões complementares, atividades e tarefas gerenciais a serem } \\
\text { desempenhadas, estruturar o sistema de atividades e organizá-las. }\end{array}$ \\
\hline Animar/dar vida & $\begin{array}{l}\text { Significa relacionar as tarefas aos recursos humanos, recrutar, selecionar e contratar } \\
\text { recursos humanos, dirigi-los à realização das visões complementares, comunicar, } \\
\text { motivar e liderar. }\end{array}$ \\
\hline Monitorar & $\begin{array}{l}\text { Envolve monitorar as realizações e os recursos usados, incluindo o tempo, comparando- } \\
\text { os às previsões e analisando as diferenças, corrigir, ajustar e melhorar. }\end{array}$ \\
\hline Aprender & $\begin{array}{l}\text { No sentido de questionar, em qualquer nível, o que foi feito e como foi feito, considerar } \\
\text { as alternativas, buscar elementos de consistência, raciocinar, imaginar, definir e redefinir } \\
\text { a visão central e as visões complementares. }\end{array}$ \\
\hline
\end{tabular}
Fonte: Adaptado de Filion (1999b).

A principal motivação para a criação do modelo de atividades do processo gerencial de empreendedores, segundo Filion (1999b) reside no fato de que, até o momento, não havia sido desenvolvida nenhuma abordagem específica utilizando os modelos obtidos a partir do estudo empírico sobre o processo gerencial de gerentes-proprietários de pequenos negócios, prevalecendo até então, o emprego da abordagem clássica POCC (planejamento, organização, comando e controle). Nesse sentido, objetiva-se nesse estudo, promover uma releitura do modelo de atividades gerencias de empreendedores proposto por Filion (1999b), 
a fim de analisar como as equipes de direção de microempresas rurais fazem uso dos elementos componentes do modelo em seus processos gerenciais.

\section{Agronegócio e agricultura familiar}

Com base nas diferentes visões sistêmicas dos Sistemas Agroindustriais, Zylbersztajn e Neves (2000) citam o conceito de agronegócio a partir de dois autores norte-americanos, John Davis e Ray Goldberg, que em 1957 lançaram o termo conhecido como agribusiness, nos EUA. Os autores apresentaram o agronegócio de forma sistêmica e integrada e não de forma isolada como até então a agricultura e a pecuária eram tratadas.

Salienta-se que os estudos e/ou gestão dos Sistemas Agroindustriais seguem duas principais correntes metodológicas, que surgiram em tempos, locais e contextos diferentes (ZYLBERSZTAJN; NEVES, 2000, p.3): Agribusiness e Commodity System Approach (CSA, do inglês para o português, Enfoque de Sistema de Commodities) e Analyse de Filière (do francês para o português, Cadeias de Produção).

O conceito de agronegócio apresenta numerosas concepções na literatura, tais como a proposta por Batalha e Souza Filho (2009), os quais compreendem o agronegócio como o conjunto de atividades e empresas agropecuárias e agroflorestais e aquelas ligadas aos insumos agropecuários e agroflorestais (defensivos animais e vegetais, adubos, máquinas, equipamentos etc.), à agroindústria de processamento e os sistemas de distribuição.

Segundo Boiko (2012) o agronegócio pode ser compreendido como um sistema, formado por sistemas menores ou subsistemas, conhecidos como Sistemas Agroindustriais (SAG's), os quais Zylbersztajn e Neves (2000) compreendem "como um conjunto de relações contratuais entre empresas e agentes especializados, cujo objetivo final é disputar o consumidor de determinado produto" (ZYLBERSZTAJN; NEVES, 2000, p.13). A análise dos SAG's exige necessariamente o estudo e identificação dos agentes que o compõe, sendo eles: produção primária, agroindústrias, distribuição agrícola e agroalimentar, comércio Internacional, consumidor e indústrias e serviços de apoio.

De acordo com o relatório Associação Catarinense de Empresas de Tecnologia (ACATE, 2015), quase metade da população mundial, cerca de 3 bilhões de pessoas, vive em áreas rurais. Desse total, cerca de 2,5 bilhões obtêm seu sustento da agricultura, tornando a atividade uma força motriz da economia, sobretudo nos países em desenvolvimento, sendo responsável por aproximadamente $75 \%$ do valor adicionado pela atividade agrícola no mundo (ACATE, 2015).

As perspectivas para 2017, mesmo com a economia voltando para os eixos, conforme a CNA (2016), são as de que o agronegócio novamente será o setor com maior crescimento. O PIB do agronegócio deve crescer $2 \%$ em 2017, enquanto o desempenho estimado para o PIB da economia é de expansão de 1,1\% (CNA, 2016). Ainda de acordo com CNA (2016) Em 2017, "o setor continuará aumentando o volume de vendas externas, a participação no comércio exterior e a geração de empregos, sendo fundamental para a recuperação econômica do país" (CNA, 2016, p.41).

O estado de Santa Catarina, localizado na região Sul do Brasil, o qual contempla o munícipio de estudo, se destaca como um dos estados com melhores indicadores econômicos e sociais. Com uma extensão territorial de $95.737,895 \mathrm{Km}^{2}$, representa $1,12 \%$ do território nacional e $16,91 \%$ da região Sul, 
contribui substancialmente para a economia do país. Conforme o Governo do Estado de Santa Catarina o setor do agronegócio se mantém competitivo e faz de Santa Catarina referência mundial em qualidade e sanidade dos rebanhos e produtos (SECRETARIA DE ESTADO DA AGRICULTURA E DA PESCA, 2016).

Ainda de acordo com o Governo do Estado com mais de 700 mil empregos diretos, o agronegócio movimenta mais de R $\$ 61$ bilhões, ou seja, 29\% do PIB catarinense. Santa Catarina se firma como grande produtor de alimentos e prova que as pequenas propriedades podem gerar renda e desenvolvimento.

Convém assinalar que, agronegócio e agricultura familiar são considerados segmentos que apresentam uma interdependência e complementariedade, uma vez que o agronegócio inclui a agricultura familiar. A pequena agricultura familiar é parte fundamental do agronegócio. Mas o que interessa na discussão agricultura familiar versus agronegócio não é o tamanho das propriedades, e sim sua gestão e sustentabilidade. Não há, portanto, confrontação de modelos de produção, mas sim migração, evolução, inovação e integração (JANK, 2017).

Introduz-se agricultura familiar assinalando que a mesma tem dinâmica e características distintas em comparação a agricultura não familiar. Pois nela, "a gestão da propriedade é compartilhada pela família e a atividade produtiva agropecuária é a principal fonte geradora de renda" (SEAD, 2016), estabelecendo-se uma relação particular entre o agricultor familiar e a terra, seu local de trabalho e moradia.

De acordo com o Censo Agropecuário de 2006 existem 4.367.902 milhões de estabelecimentos da agricultura familiar no Brasil, o que representa $84,4 \%$ dos estabelecimentos rurais do país. Esse contingente de agricultores familiares compreendia uma área de 80,25 milhões de hectares, ou seja, $24,3 \%$ do total do território ocupado pelas propriedades agropecuárias brasileiras (FRANÇA; DEL GROSSI; MARQUES, 2009).

Além disso, conforme o censo referido, a agricultura familiar constitui a base econômica de $90 \%$ dos municípios brasileiros com até 20 mil habitantes, responde por $35 \%$ do produto interno bruto nacional e absorve $40 \%$ da população economicamente ativa do país. Participa ainda, em $87 \%$ da produção nacional da mandioca, $70 \%$ da produção de feijão, $46 \%$ do milho, $38 \%$ do café, $34 \%$ do arroz e $21 \%$ do trigo do Brasil. Na pecuária, é responsável por $60 \%$ da produção de leite, além de $59 \%$ do rebanho suíno, $50 \%$ das aves e $30 \%$ dos bovinos do país.

Fauth (2008) ressalta que a agricultura familiar configura como uma das principais fontes de produção de alimentos, de renda e de emprego para a população rural, além de favorecer o cumprimento de exigências ambientais, como a conservação da biodiversidade. Revelando-se, dessa forma, como uma das melhores formas de ocupação do espaço rural.

A Lei da Agricultura Familiar e dos Empreendimentos Familiares Rurais (Lei 11.326 de 24 de julho de 2006), considera agricultor familiar e empreendedor familiar rural aquele que pratica atividades no meio rural, atendendo, simultaneamente, aos seguintes requisitos:

I - Não detenha, a qualquer título, área maior do que 4 (quatro) módulos fiscais; II Utilize predominantemente mão-de-obra da própria família nas atividades econômicas do seu estabelecimento ou empreendimento; III - Tenha percentual mínimo da renda familiar originada de atividades econômicas do seu estabelecimento ou empreendimento; IV - Dirija seu estabelecimento ou empreendimento com sua família (BRASIL, 2006a, p.1). 
Identifica-se, nesse sentido, que a delimitação legal do conceito de agricultor familiar combina com critérios como tamanho da propriedade, predominância familiar da mão-de-obra e da renda e, gestão familiar da unidade produtiva. Sob essa óptica, observa-se a importância estratégica das políticas públicas.

Em termos de políticas públicas destinadas a agricultura familiar, ressalta-se a institucionalização, em 1995, do Programa Nacional de Fortalecimento da Agricultura Familiar- Pronaf (BIANCHINI, 2015). A criação do Pronaf pode ser "traduzida como uma das respostas à pressão e às negociações políticas dos movimentos sociais da agricultura familiar com o governo" (MALDANER, 2014, p.26).

A existência e a implementação do Pronaf vêm favorecendo o reconhecimento público da categoria social de agricultor familiar, bem como sua expressão econômica e social na sociedade brasileira (IBASE, 2006). Dessa maneira, assume fundamental importância, pois configura como um dos principais apoiadores da agricultura familiar e desde sua institucionalização como primeira política pública direcionada especificamente aos agricultores familiares, segue cumprindo seu maior objetivo: "o de propiciar condições para aumentar a sua produção, gerando emprego e renda, melhorando a qualidade de vida, inserindo-se no mercado e modernizando seu sistema produtivo (FERNANDES, 2013, p. 53).

O estado de Santa Catarina é um dos estados com maior número de agricultores familiares do país. Esses agricultores familiares detêm cerca de 170 mil estabelecimentos agropecuários de todo o estado, o que corresponde a $87 \%$ do total. Toda a produção dos agricultores ocupa mais de 2.500 .000 de hectares, que representam $44 \%$ do total da zona rural catarinense. Em relação aos principais produtos de origem vegetal e animal, responde pela produção de $93 \%$ da mandioca, $87 \%$ do leite, $77 \%$ do milho, $73 \%$ do feijão, $68 \%$ das aves, $67 \%$ dos suínos, $65 \%$ dos bovinos, $64 \%$ do arroz, $30 \%$ da soja e $17 \%$ do trigo (SEAD, 2016).

\section{MÉTODOS}

A pesquisa se caracteriza como um estudo de múltiplos casos de natureza qualitativa. O método qualitativo é apropriado ao estudo de um nível de realidade que não pode ser quantificado, por se relacionar a motivos, valores e atitudes, aspectos correspondentes a um espaço mais profundo de relações e processos que não se pode reduzir à operacionalização de variáveis (MINAYO, 2004).

De acordo com os conceitos propostos por Vergara (2013, p.41), essa pesquisa se classifica segundo dois critérios básicos: quanto aos fins e quanto aos meios. No que tange aos fins, classifica-se como descritiva, visto que expõe características de determinada população ou fenômeno, aqui compreendidas como as características dos processos de gestão das equipes de direção de microempresas rurais. E quanto aos meios, classifica-se como pesquisa de campo, realizada no local onde ocorre o fenômeno em estudo, dispondo de elementos para explicá-lo.

Optou-se pelo estudo multicasos devido ao maior potencial explicativo, além de não se restringir às peculiaridades do processo de gestão de uma única equipe de direção. $O$ estudo de múltiplos casos tem o potencial de criar teorias mais robustas, considerando-se que "as proposições são fundamentadas com maior profundidade na evidência empírica variada" (EISENHARDT; GRAEBNER, 2007, p. 27). Contudo, essa decisão não envolveu pretensões de generalizá-los.

O objeto de estudo desta pesquisa foi o processo de gestão das equipes de direção de microempresas rurais, situadas no Oeste Catarinense. A delimitação do número de casos foi orientada pela pesquisa de campo e pela teoria, levando-se em consideração que o principal interesse do estudo de múltiplos casos é 
conceitual (MILES; HUBERMAM, 1994). A escolha dos casos foi intencional, por meio de amostragem teórica, num esforço de estabelecer amostras que oferecessem aquisição de novos conhecimentos.

Este tipo de amostra é estabelecido em paralelo à análise, de modo a se poder verificar se a saturação teórica ocorreu, significando que novos itens acrescentados à amostra não conseguem gerar mais contribuições para se responder à pergunta de pesquisa (EISENNHARDT, 1989). Em outras palavras, até que as contribuições geradas por dados coletados em novos casos sejam muito similares ou simplesmente repitam as contribuições provenientes dos dados dos casos anteriores.

No processo de montagem da amostra de pesquisa foram seguidos como critério a classificação dos imóveis rurais, conforme apresentada pelo Instituto Nacional de Colonização e Reforma Agrária - INCRA (2016), o qual classifica os imóveis em relação ao tamanho da área. Assim sendo, foram considerados microempresários rurais, para fins do estudo, aqueles que de acordo com a classificação apresentada pelo Incra (2016), possuíssem "Minifúndio ou Pequena propriedade", no Oeste Catarinense. As principais motivações para escolha dessa região associam-se a importância e representatividade do setor agropecuário, composto predominantemente por agricultores familiares.

A amostragem teórica foi realizada, em termos práticos, em dois eventos de amostragem: um caso inicial foi selecionado, e com base na análise dos dados referentes a essa microempresa rural, outros casos adicionais foram sequencialmente selecionados.

Os dados foram coletados por meio de entrevistas em profundidade, conduzidas face a face, junto aos microempresários rurais, no primeiro semestre de 2017. Elas foram gravadas e realizadas nas sedes das empresas, alcançando a duração média de cinquenta minutos. Foram entrevistadas oito equipes de direção de oito comunidades diferentes na região do Oeste Catarinense. A equipe de direção de uma Pequena Empresa é entendida aqui como a equipe formada por coproprietários-dirigentes atuantes na decisão estratégica (MAIA; LIMA,2016). O Quadro 2 sintetiza detalhes sobre essas equipes e fornece informações a respeito das empresas rurais. 
Quadro 2- Perfil das equipes de direção estudadas e características de suas propriedades.

\begin{tabular}{|c|c|c|c|c|c|}
\hline & EQUIPES & $\begin{array}{l}\text { IDADE } \\
\text { (anos) }\end{array}$ & $\begin{array}{l}\text { ATUAÇÃO } \\
\text { (anos) }\end{array}$ & $\begin{array}{c}\text { ATIVIDADES } \\
\text { DESENVOLVIDAS }\end{array}$ & FATURAMENTO \\
\hline \multirow{3}{*}{1} & Codirigente Pai & 52 & \multirow{3}{*}{54} & \multirow{3}{*}{$\begin{array}{l}\text { Avicultura, Piscicultura e } \\
\text { Pecuária de Corte. }\end{array}$} & \multirow{3}{*}{$\begin{array}{l}\text { De } 04 \text { a } 06 \\
\text { salários mínimos }\end{array}$} \\
\hline & Codirigente Mãe & 48 & & & \\
\hline & Codirigente Filha & 22 & & & \\
\hline \multirow{5}{*}{2} & Codirigente Pai & 52 & \multirow{5}{*}{42} & \multirow{5}{*}{ Grãos } & \multirow{5}{*}{$\begin{array}{l}\text { De } 01 \text { a } 03 \\
\text { salários mínimos }\end{array}$} \\
\hline & Codirigente Mãe & 44 & & & \\
\hline & Codirigente Filha & 22 & & & \\
\hline & Codirigente Avô & 74 & & & \\
\hline & Codirigente Avó & 70 & & & \\
\hline \multirow{2}{*}{3} & Codirigente Marido & 50 & \multirow[b]{2}{*}{12} & \multirow{2}{*}{$\begin{array}{l}\text { Pecuária de Corte, } \\
\text { Suinocultura e } \\
\text { Reflorestamento }\end{array}$} & \multirow{2}{*}{$\begin{array}{l}\text { De } 07 \text { a } 09 \\
\text { salários mínimos }\end{array}$} \\
\hline & Codirigente Esposa & 45 & & & \\
\hline \multirow{2}{*}{4} & Codirigente Marido & 56 & \multirow[b]{2}{*}{7} & \multirow{2}{*}{ Avicultura } & \multirow{2}{*}{$\begin{array}{c}\text { De } 04 \text { a } 06 \\
\text { salários mínimos }\end{array}$} \\
\hline & Codirigente Esposa & 56 & & & \\
\hline \multirow{2}{*}{5} & Codirigente Marido & 55 & \multirow[b]{2}{*}{30} & \multirow{2}{*}{$\begin{array}{l}\text { Pecuária de leite e Produção } \\
\text { de grãos }\end{array}$} & \multirow{2}{*}{$\begin{array}{l}\text { Mais de } 12 \\
\text { salários mínimos }\end{array}$} \\
\hline & Codirigente Esposa & 50 & & & \\
\hline \multirow{2}{*}{6} & Codirigente Marido & 51 & \multirow{2}{*}{28} & \multirow{2}{*}{ Pecuária de leite e Avicultura } & \multirow{2}{*}{$\begin{array}{l}\text { Mais de } 12 \\
\text { salários mínimos }\end{array}$} \\
\hline & Codirigente Esposa & 47 & & & \\
\hline \multirow{4}{*}{7} & Codirigente Pai & 57 & \multirow{4}{*}{34} & \multirow{4}{*}{ Pecuária de leite e Avicultura } & \multirow{4}{*}{$\begin{array}{c}\text { De } 10 \text { a } 12 \\
\text { salários mínimos }\end{array}$} \\
\hline & Codirigente Mãe & 58 & & & \\
\hline & Codirigente Filho & 29 & & & \\
\hline & Codirigente Nora & 30 & & & \\
\hline \multirow{5}{*}{8} & Codirigente Pai & 56 & \multirow{5}{*}{44} & \multirow{5}{*}{$\begin{array}{l}\text { Pecuária de leite e Produção } \\
\text { de Grãos }\end{array}$} & \multirow{5}{*}{$\begin{array}{c}\text { De } 10 \text { a } 12 \\
\text { salários mínimos }\end{array}$} \\
\hline & Codirigente Mãe & 51 & & & \\
\hline & Codirigente Filho 1 & 27 & & & \\
\hline & Codirigente Nora & 26 & & & \\
\hline & Codirigente Filho 2 & 24 & & & \\
\hline
\end{tabular}

Fonte: Dados da pesquisa (2017).

Para melhor condução das entrevistas foi utilizado um roteiro semiestruturado de coleta de dados, cuja flexibilidade possibilitou a introdução de variações de acordo com cada entrevistado. $O$ roteiro foi desenvolvido com o cuidado de resguardar sua flexibilidade, permitindo adaptações com acréscimos ou exclusão de temas de acordo com os dados surgidos ao longo de cada entrevista. Nele um conjunto de questões sobre o tema foi organizado, relacionadas desde à gestão dos empreendimentos, visualização do negócio, envolvendo aspectos históricos, aprendizado e visão de futuro.

Reforça-se que, o modelo utilizado como base para a construção do roteiro, condução da coleta de dados e as suas análises foi o proposto Filion (1999b), intitulado Modelo Conceitual do Potencial Empreendedor (Figura 1), o qual é dividido em cinco elementos: aprender, monitorar, animar/dar vida, criar e visualizar.

A análise dos resultados foi realizada por meio da análise de conteúdo, conforme as orientações de Bardin (1977). Sendo assim, para fins dessa pesquisa procedeu-se da seguinte forma: a) pré-análise, que consistiu na organização do material que forneceu informações para a análise propriamente dita. Ou seja, primeiramente ocorreu a transcrição das entrevistas e a seguir, leitura de todas as entrevistas transcritas; b) 
a exploração do material, etapa concernente à codificação, decomposição e enumeração dos indicadores e variáveis pertinentes, de acordo com os relatos transcritos. Dentro de uma proposta de análise temática categorial verificou-se os temas frequentes nas entrevistas, deles formaram-se categorias relacionadas ao processo gerencial dos entrevistados, por fim; c) tratamento dos resultados obtidos e interpretação, aqui os resultados são tratados de maneira a se tornarem significativos. Houve escolha de trechos específicos que melhor permitiam a análise frente às distintas entrevistadas, em um movimento de agrupamento.

Nessa última etapa da análise de conteúdo, delimitam-se as categorias temáticas, com base nos dados coletados. Nela, torna-se importante o uso da intuição, bem como de uma análise crítica e reflexiva dos discursos evidenciados no decorrer das entrevistas (BARDIN, 1977).

Terminadas as considerações sobre o método adotado neste trabalho, o capítulo seguinte apresenta os resultados e sua discussão.

\section{O PROCESSO DE GESTÃO DAS MICROEMPRESAS RURAIS}

Para melhor compreender o processo de gestão realizado pelas equipes de direção das oito microempresas estudadas, faz-se necessário primeiramente contextualizar suas realidades. Isso será feito a seguir por meio da apresentação do perfil das equipes de direção pesquisadas e do histórico das empresas objeto de estudo.

\section{Histórico das empresas rurais}

Em relação à origem do patrimônio, $75 \%$ dos entrevistados teve seu patrimônio oriundo de herança recebida pelos seus pais e outros $25 \%$ obtiveram o seu atual patrimônio com recursos próprios provenientes de outras atividades, muitas destas ligadas à exploração da terra. Há casos em que embora tivesse recebido parte por meio de herança de familiar, conseguiram aumentá-lo com renda oriunda do próprio patrimônio e/ou por meio de financiamentos.

Outro fator que merece atenção é o tempo de atuação na agricultura, pois considerando o tempo de ocupação dos imóveis pelas famílias: $50 \%$ delas detém a posse a mais de 30 anos; $25 \%$ entre 20 e 30 anos; e $25 \%$ detém a posse de 0 a 20 anos.

Dessa maneira, o fator "tempo na agricultura" é destaque, pois em todas as propriedades entrevistadas seus dirigentes relataram que em nenhum momento deixaram a atividade rural. Observa-se que esses agricultores do município sempre investiram na atividade rural, fazendo da agricultura familiar a principal fonte de renda da família. No entanto, também é perceptível que, embora o processo sucessório venha ocorrendo nas propriedades, em alguns casos a continuidade da propriedade está ameaçada, por não haverem sucessores.

Com base nas especificidades do processo histórico das empresas rurais, observou-se que em suas trajetórias, todas as propriedades estudadas depararam-se com dificuldades e precisaram superar diversos desafios e incertezas, no entanto, as mudanças e as conquistas ao longo da caminhada merecem destaque, fruto de muito trabalho, persistência e dedicação, conduzindo-as ao momento atual. 
Quando questionados sobre o significado da empresa familiar, evidenciou-se a partir de alguns relatos a importância atribuída a família e a propriedade, representando uma história de vida, trabalho, união, força, bem-estar, resultado de muito esforço e dedicação e, acima de tudo, um lugar bom para se morar, tranquilo e agradável.

Elementos do processo de gestão

Com base nos principais elementos do processo gerencial de empreendedores, conforme modelo teórico de Filion (1999b), buscou-se analisar as entrevistas com as equipes de direção de microempresas rurais estudadas. Frente as evidências apontadas pelo discurso dos entrevistados, torna-se possível promover uma releitura do modelo de Filion (1999b), caracterizando os elementos do processo gerencial de empreendedores, quais sejam: visualizar; criar uma arquitetura de negócios; animar/dar vida; monitorar e aprender, na sequência cada elemento será explorado.

Assim procedendo, apresenta-se, inicialmente, as evidências da expressão do processo de visualização. Trata-se de um elemento central da estrutura na qual os empreendedores desempenham suas atividades gerenciais, ou ainda, o coração do processo de empreendedorismo está relacionado ao desenvolvimento e implementação do processo visionário. Para Filion (1999b) o elemento visualizar envolve: identificar um interesse num setor de negócios; entender um setor de negócios; detectar uma oportunidade de negócios; imaginar e definir um contexto organizacional e planejar.

No contexto de microempresas rurais, no qual se insere as equipes de direção pesquisadas, percebese que as empresas rurais representam uma inovação, uma oportunidade de se destacar nesse setor de negócios vital para a economia e para o sustento do mundo, considerando que se trata essencialmente da produção de alimentos. Quanto as motivações dos empresários rurais em investir ou permanecer no setor agrícola, foram identificados alguns motivos impulsionadores como: o fato de gostar do que fazem, sentirem realizados e felizes no meio rural. Outro fato impulsionador é a experiência de vida de cada agricultor, que influencia todo o processo decisório. Com base nessas experiências, o agricultor aprimora suas atitudes, identificando e corrigindo erros, como também obtendo experiências positivas e multiplicando-as com outros agricultores (LIMA; PARTELI; LOOSE, 2015).

Em relação ao conhecimento adquirido e repassado do setor, nos casos estudados esse processo foi transmitido de geração para geração, relatando que sempre moraram no campo e que o incentivo a permanência e continuidade tem essência familiar sobretudo dos pais. Ou seja, o conhecimento sobre o setor é baseado no convívio, experiências e aprendizagem, não demandando qualificação prévia por parte dos empresários. No entanto, frente às novas exigências nos processos de gestão, visualizaram a necessidade da busca por qualificação. Isso tem contribuído para a definição de uma nova visão a respeito do futuro no empreendimento, assinalando a participação em cursos e palestras, onde as equipes de direção reforçam a importância e as contribuições dessa participação na condução e gerenciamento do empreendimento. Entretanto, há casos em que o tempo dedicado é raro ou inexistente (Quadro 3). 
Quadro 3 - Elemento Visualizar do processo gerencial de empreendedores e relatos dos entrevistados.

\begin{tabular}{|c|c|}
\hline Elemento teórico & Relatos dos entrevistados \\
\hline \multirow{2}{*}{$\begin{array}{l}\text { VISUALIZAR } \\
\text { Identificar um setor, } \\
\text { entendê-lo, detectar } \\
\text { oportunidades, definir } \\
\text { um contexto e } \\
\text { planejar. }\end{array}$} & $\begin{array}{l}\text { "[...] a ampliação das atividades, modernização, maior produtividade, qualidade e } \\
\text { investimentos em melhoramento genético são alguns dos motivos que nos levaram a } \\
\text { permanecer e investir na agricultura [...] e as atividades que possuímos hoje estão } \\
\text { relacionadas principalmente ao conhecimento na área, interesse, manejo mais fácil se } \\
\text { comparado a outras atividades e retorno financeiro [...] (Equipe de direção 8) ". }\end{array}$ \\
\hline & $\begin{array}{l}\text { "[...] na medida do possível, sempre buscamos participar de cursos e palestras, pois sempre } \\
\text { se aprende. O maior aprendizado é o de conhecer novas técnicas, novidades do setor [...] é } \\
\text { uma forma de manter-se atualizado e informado sobre as exigências do mercado [...] } \\
\text { acompanhar tendências buscando melhorar o processo produtivo e torná-lo mais fácil [...] } \\
\text { (Equipe de direção } 7 \text { )". }\end{array}$ \\
\hline
\end{tabular}

Fonte: Dados da pesquisa (2017).

Contudo, quanto a abordagem dos principais fatores levados em consideração para a definição das atividades a serem desempenhadas no empreendimento pode-se destacar: o potencial da propriedade (terreno, fertilidade, etc.), a complementariedade e interdependência entre as atividades, a mão de obra e tecnologias disponíveis, o investimento necessário, a viabilidade e lucratividade e, sobretudo, o conhecimento da atividade.

No que se refere ao elemento criação de uma arquitetura de negócios exposto por Filion (1999b), para os empreendedores, esse processo é baseado no espaço de mercado que desejam ocupar (FILION 1999b). Os elementos componentes dessa atividade são: formular visões complementares, atividades e tarefas gerenciais a serem desempenhadas; estruturar o sistema de atividades e organizar.

Nos casos estudados, fora constatado que não existe uma organização formal das atividades e tarefas gerenciais a serem desempenhadas dentro das empresas e recursos humanos necessários. Embora em alguns casos afirmem que o trabalho é dividido, cada um com suas responsabilidades, no geral, a família realiza em conjunto as tarefas da propriedade, ou cada um assume uma parte do serviço a ser feito. $\mathrm{O}$ trabalho em conjunto, a união e o diálogo são a base das empresas estudadas.

"[...] não existe divisão entre o trabalho de homem e de mulher, de um ou de outro [...] não há uma divisão clara das tarefas para a realização das atividades, sempre buscamos realizar as atividades em conjunto e alternando as tarefas de cada um, todos se ajudam [...] assim todos têm conhecimento sobre tudo. E quando se fala em trabalho conjunto é preciso ouvir a opinião de todos, organizar-se e manter o entendimento (Equipe de direção 1) ". 
As evidências demonstraram que a função "organizar" apresenta lacunas no que se refere a organização pessoal, ausência de estruturação de cargos e tarefas de todos os envolvidos nos trabalhos. Na tentativa de formalizar o processo, uma possibilidade seria a elaboração do organograma da empresa, permitindo melhor visualização do funcionamento da empresa, pois estaria indicado quem e quais as tarefas que cada um desempenharia.

"[...] para o futuro na atividade, pretendemos continuar, mas sempre buscando melhorar, aperfeiçoar, buscar novas tecnologias[...] o que mais influência nos resultados da atividade são variações nos preços e as condições climáticas [...], mas por se tratar do ramo de alimentos acreditamos que sempre vai precisar e tende a crescer cada dia mais [...] [...] vai se tornar cada dia mais exigente, principalmente a qualidade[...] (Equipe de direção 2)".

As famílias trabalham duro e são comprometidas com o que fazem, analisam tendências para o futuro nas atividades, adotam a atitude de inovar continuamente. Identificam e atendem às necessidades e expectativas de seus clientes, com vistas a criar vantagem competitiva frente a concorrência. Contudo a inexistência de uma estrutura formal da empresa pode estar impossibilitando os proprietários aumentar sua carteira de clientes e até mesmo conquistar novos mercados.

O terceiro elemento do processo gerencial de empreendedores, animação da estrutura de negócios, revela aspectos importantes sobre a postura do empreendedor. O processo de animar/dar vida resume-se em: ligar as tarefas aos recursos humanos; recrutar, selecionar e contratar recursos humanos; dirigir os recursos humanos para a realização das visões complementares; comunicar; motivar e liderar. Empreendedores de sucesso investem mais tempo, energia e recursos que os demais em recrutamento, seleção e treinamento de recursos humanos competentes e adequados (FILION, 1999b; LIMA; PARTELI; LOOSE, 2015).

No que se refere a busca por conhecimento, as equipes de direção estudadas revelam que embora não invistam especificamente em treinamento, a busca por qualificação é algo presente na grande maioria dos relatos. Esses enfatizam em seus discursos a importância que os recursos humanos têm para o sucesso do empreendimento, uma vez que há dependência destes para o desempenho das atividades.

Considerando que se tratam de empresas familiares, pode-se destacar uma característica importante do trabalho: a comunicação. O diálogo entre todos os envolvidos é percebido como a base para um bom gerenciamento, bem como para manter-se motivados no desempenho de suas atividades. Afinal, mesmo se tratando de mão de obra familiar, é necessário que a comunicação entre os indivíduos seja eficiente. Cella (2002) ressalta que a adoção de uma comunicação clara deve ser uma das atitudes de um agricultor. O bom produtor não é centralizador e deve ter a habilidade de fazer com que todos os envolvidos nas atividades da propriedade compreendam os objetivos e tomem atitudes para alcança-los. É de extrema importância que o agricultor saiba influenciar pessoas e despertar seguidores para poder repassar suas experiências, descrever procedimentos e tecnologias implantadas na propriedade, facilitando o manejo das atividades agropecuárias (Quadro 4). 
Quadro 4- Elemento Animar/Dar vida do processo gerencial de empreendedores e relatos dos entrevistados.

\begin{tabular}{|c|c|}
\hline Elemento teórico & Relatos dos entrevistados \\
\hline \multirow[t]{2}{*}{ ANIMAR/DAR VIDA } & $\begin{array}{l}\text { "[...] Um dos aspectos que consideramos muito importante para o bom andamento da } \\
\text { propriedade é a comunicação, [...] [...] o diálogo, seja de pequenas coisas ou de aspectos } \\
\text { mais importantes. A base para um bom relacionamento, para um trabalho eficiente, para um } \\
\text { bom gerenciamento e para uma família unida é o diálogo (Equipe de direção 6)". }\end{array}$ \\
\hline & $\begin{array}{l}\text { "[...] a motivação, o incentivo uns aos outros no dia a dia é algo natural, }[\ldots][\ldots] \text { sempre } \\
\text { buscamos não desanimar diante das dificuldades, sempre seguir em frente encarrar o que } \\
\text { não deu certo como aprendizado [...] (Equipe de direção 4)". }\end{array}$ \\
\hline $\begin{array}{l}\text { Ligar as tarefas ao } \mathrm{RH} \\
\text { recrutar, selecionar } \\
\text { contratar, comunicar, } \\
\quad \text { motivar e liderar }\end{array}$ & $\begin{array}{l}\text { "[...] sobre o compartilhamento do conhecimento, estamos sempre abertos ao diálogo, a } \\
\text { troca de informações, [...] todos tem a oportunidade de estar conversando, demonstrando o } \\
\text { que aprendem e podendo aplicar na prática aquilo que consideram importante para o } \\
\text { funcionamento e desenvolvimento da propriedade [...] (Equipe de Direção 1)". }\end{array}$ \\
\hline
\end{tabular}

Fonte: Dados da pesquisa (2017).

Quanto ao processo de liderança nos empreendimentos, foi identificado a presença informal da figura do líder, que busca dialogar com todos, aberto a opiniões, que com naturalidade conquista o respeito e admiração do seu entorno. Essa figura, nos casos estudados, está associada a figura do proprietário, que trabalha em conjunto com os demais, troca informações, ouve, discute e influência na decisão final.

A monitoração, outro elemento componente do modelo de Filion (1999b) deve ser compreendida no sentido de monitorar as realizações e os recursos usados como: tempo, comparação com as previsões, e análises de diferenças, com o intuito de corrigir, ajustar e fazer melhorias (FILION, 1999b; DORNELAS, 2012). A fim de verificar de que forma o monitoramento se faz presente nas empresas rurais e como ocorre esse processo, constatou-se que somente três propriedades monitoram formalmente suas atividades. Duas propriedades mantêm registros e controles totais das despesas, e uma realiza controles, mas não da propriedade com um todo, apenas de atividades isoladas. Nos casos em que os registros e controles são feitos, os mesmos são administrados eletronicamente, monitorados em caráter periódico, algumas vezes mensalmente e, em alguns casos, a cada safra.

Já nas cinco equipes de direção restantes, verificou-se que as mesmas não possuem registros e controles estabelecidos formalmente e muitas vezes as informações da gestão são confiadas à memória dos proprietários. Logo, no caso de uma transição da gestão, quem assumisse os negócios no futuro, não teria histórico da propriedade (Quadro 5). 
Quadro 5- Elemento Monitorar do processo gerencial de empreendedores e relatos dos entrevistados.

\begin{tabular}{|c|c|}
\hline Elemento teórico & Relatos dos entrevistados \\
\hline \multirow{3}{*}{$\begin{array}{l}\text { MONITORAR } \\
\text { Monitorar as } \\
\text { realizações e } \\
\text { comparar com as } \\
\text { previsões, } \\
\text { analisar as } \\
\text { diferenças, } \\
\text { corrigir, ajustar e } \\
\text { melhorar. }\end{array}$} & $\begin{array}{l}\text { "[...] realizamos registros de despesas e receitas e controles de venda, de insumos, de produção, } \\
\text { controle de estoque e custos incorridos, mensalmente e a cada final de safra [...] e são feitos } \\
\text { eletronicamente. [...] os benefícios desse processo de registros e controles são muitos, pois temos } \\
\text { exatidão naquilo que foi gasto, o que está, bom e o que é preciso mudar [...] [...] são pequenas } \\
\text { coisas, que quando anotadas, gera uma certeza do que foi feito e do resultado que gerou, o que } \\
\text { está bom e o que é preciso aperfeiçoar (Equipe de direção 2) ". }\end{array}$ \\
\hline & $\begin{array}{l}\text { "[...] não realizamos controles e registros constantes e escritos e nem análise sobre os resultados, } \\
\text { tudo é apenas conversado [...] e embora não temos nada anotado, na nossa memória sabemos } \\
\text { o quanto gastamos, no que gastamos, os custos, o que vendemos, o que entrou, o que é preciso } \\
\text { mudar, fazer diferente, melhorar na propriedade, a execução das atividades e gerar resultados } \\
\text { mais satisfatórios [...] (Equipe de direção 5)". }\end{array}$ \\
\hline & $\begin{array}{l}\text { "[...] avaliamos os resultados com base naquilo que está na nossa memória, naquilo que achamos } \\
\text { que gastamos, mas não temos uma exatidão de qual foi o resultado, está tudo na ponta da língua } \\
\text { [...] e embora sabemos dos benefícios de registrar, controlar as atividades, inclusive porque } \\
\text { aprendemos isso em um curso do qual participamos, ainda não nos empenhamos e policiamos a } \\
\text { começar [...] (Equipe de Direção } 3 \text { )". }\end{array}$ \\
\hline
\end{tabular}

Fonte: Dados da pesquisa (2017).

Observou-se, com base nas evidências, que existe, mesmo informalmente, um monitoramento da parte interna da organização, promovendo observações do desenvolvimento de seus negócios. Essa forma de monitorar ressalta em avaliações sobres suas atividades no sentido de diferenciação em relação a oferta de melhores produtos e serviços de qualidade.

Considerando que empreendedores de sucesso nunca param de aprender, Filion (1999b) expõe que a essa categoria consiste em questionar o que foi feito e como foi feito, considerar as alternativas, buscar elementos de consistência, relacionar, imaginar e definir e redefinir a visão central e as visões complementares.

As evidências demonstram que, apesar das dificuldades e desafios enfrentados diariamente e incertezas que envolvem o setor, sempre buscam contorná-las da melhor forma, transformando-as em aprendizado para novas situações. Desse modo, valida-se a concepção apresentada por Filion (1999b) de que "ao percorrer o processo visionário, empreendedores tornam-se mais motivados a aprender" (FILION, 1999b, p.15).

"[...] como aprendizado podemos destacar o fato de sempre estar buscando aperfeiçoamento, buscando aprender com quem possui mais experiência, [...] estar sempre disposto a aprender, a melhorar, a inovar, a mudar. [...] [...] aprender para adquirir maior experiência no setor, para melhorar a propriedade e mantê-la organizada [...] (Equipe de direção 8) ". 
De modo geral, os dirigentes têm aprendido na condução da empresa ao longo dos anos de gerenciamento e de que modo essa aprendizagem contribui para a correção de erros, ajustes e adaptação na empresa. Observou-se que há uma preocupação das equipes de direção na busca por aperfeiçoamento, inovação e conhecimento, a fim de oferecer aos seus clientes produtos de qualidade, que atendam às suas necessidades e expectativas, oportunizando a conquista de melhores resultados e, consequentemente, melhoria na qualidade de vida familiar e sustentabilidade no mercado.

"[...] Além disso, a interação com outras propriedades, o compartilhamento do conhecimento é muito importante, pois permite conhecer outras realidades, manejos, comparar resultados [...] é uma troca de experiências, que possibilita ver o que há de bom nas outras propriedades e trazer para a nossa e até mesmo relatos de problemas e dificuldades que farão com que o mesmo não se repita na nossa [...] (Equipe de direção 4)".

Em relação às perspectivas das equipes de direção quanto ao futuro da empresa, seus planos e, sobretudo, o processo sucessório, alguns aspectos se destacam: planos de expansão, aperfeiçoamento, incertezas, inovação, continuidade e estagnação.

"[...] O maior aprendizado ao longo dos anos na agricultura é o fato de sempre buscar melhorar [...] buscar novas tecnologias, inovar [...] (Equipe de direção 3). "

Com base no modelo teórico proposto por Filion (1999b), pôde-se constatar que as oito equipes de direção investigadas apresentam sinais de processos de gestão, uma vez que apresentaram resultados satisfatórios em relação à concordância dos elementos investigados: visualizar, criar uma arquitetura de negócios, animar/dar vida, monitorar e aprender. Demonstrando que os proprietários de empresas rurais familiares, possuem condições de serem consideradas empreendedores no seu setor.

\section{CONSIDERAÇÕES FINAIS}

Após a elaboração das análises, nesse momento expõem-se algumas conclusões do estudo. Para atingir os objetivos que norteiam o presente estudo, buscou-se discutir as características dos processos de gestão das equipes de direção de microempresas rurais situadas em uma cidade de pequeno porte, considerando a importância do setor agropecuário para a economia do referido município, composto predominantemente de agricultores familiares.

Sendo assim, como base a discutir as características dos processos de gestão observadas nos agricultores familiares do município, fez-se uma releitura do processo de gerenciamento empreendedor proposto por Filion (1999b). Com base nos resultados, observou-se que os agricultores familiares estudados se caracterizam como empreendedores em seu setor de atuação, posto que apresentaram resultados satisfatórios em referência aos elementos investigados.

Frente as práticas adotadas nos processos de gerenciamento dos agricultores familiares, sejam elas formais ou informais, e relacionando-as ao processo de gerenciamento empreendedor de Filion (1999b), algumas características merecem ser destacadas: conhecimento do setor de atuação; busca por qualificação e aperfeiçoamento; realização do trabalho conjuntamente e predominância da organização informal das atividades, tarefas e responsabilidades; comprometimento e amor pelo que fazem; importância do diálogo e 
da presença do líder informal; conservam o monitoramento, mesmo que de maneira informal; aprendizado relacionado a troca de experiências e busca por aperfeiçoamento; perspectivas de inovar e expandir ou apenas manter a propriedade e, sucessão familiar como oportunidade ou incerteza. Nessa perspectiva, ressalta-se ainda a importância dada à família, alicerçada na união, diálogo e participação de todos.

O estudo permitiu constatar ainda, que há equilíbrio entre os agricultores familiares que tem na sua atividade a simples tarefa de sobrevivência, de manter a propriedade e àqueles que possuem objetivos e sonhos para seu negócio rural e que Ihes dão motivação para crescer, investir e inovar os processos da propriedade, na busca por resultados mais eficientes, eficazes e efetivos, estabelecendo vantagem competitiva frente a concorrência e, consequentemente, garantindo sua sustentabilidade no mercado.

Em uma visão sistêmica, pode-se concluir que os agricultores familiares do município em estudo classificam-se como empreendedores, considerando a análise dos elementos do processo de gerenciamento empreendedor de Filion (1999b).

Sugere-se para futuras pesquisas um olhar a partir de uma nova lente teórica, a qual poderá fornecer insights mais significativos sobre a pesquisa em processo de gestão empreendedora em equipes de direção. Ainda como sugestão, para esse tipo de empresa, novos estudos justificam-se diante da necessidade de modelos conceituais particularizados visando mais conhecimento sobre os seus processos de gestão. Como limitação encontrada ressalta-se a precariedade de pesquisas que foquem os processos de gestão em microempresas rurais.

\section{REFERÊNCIAS}

ASSOCIAÇÃO CATARINENSE DE EMPRESAS DE TECNOLOGIA (ACATE). Agronegócio e Tecnologia: Santa CatarinaAnuário 2015. Disponivel em: <https://.acate.com.br/system/files/arquivos/anuario2015.pdf>. Acesso em: 17 set.2016.

BARDIN, L. Análise de conteúdo. Tradução de Luís Antero Reta e Augusto Pinheiro. Lisboa: Presses Univcrsitaires de France, 1977.

BATALHA, M. O.; SOUZA FILHO, H. M. Analisando a Competitividade de Cadeias Agroindustriais: Uma proposição Metodológica. In: BATALHA, M.O.; SOUZA FILHO, H. M. (Orgs). Agronegócio no Mercosul: Uma Agenda para o Desenvolvimento. São Paulo. Atlas, 2009.

BIANCHINI, V. Vinte anos do PRONAF 1995 - 2015: avanços e desafios. Brasília: SAF/MDA, 2015. 113 p. Disponível em: <http://www.mda.gov.br/sitemda/sites/sitemda/files/ceazinepdf/PRONAF_20_ANOS_VALTER_BIANCHINI.pdf>. Acesso em: 05 jan.2017.

BOIKO, T. J. P. Produção e Sistemas Agroindustriais. Centro Universitário de Maringá: Maringá, 2012.

BRASIL. Lei $n^{\circ}$. 11326, de 24 de julho de 2006. Estabelece as diretrizes para a formulação da Política Nacional da Agricultura Familiar e Empreendimentos Familiares Rurais. Brasília. Disponível em: <http://www.planalto.gov.br/ccivil_03/_ato2004-2006/2006/lei//11326.html>. Acesso em: 26 out.2016.

CASTRO, A. M. G. Análise da competitividade de cadeias produtivas. In: WORKSHOP CADEIAS PRODUTIVAS E EXTENSÃO RURAL NA AMAZÔNIA, 2000, Manaus. Anais... Manaus: Embrapa, 2000.

CELLA, D. Caracterização dos Fatores Relacionados ao Sucesso de Um Empreendedor Rural. 2002. 166f. Dissertação (Mestrado em Ciências) - Universidade de São Paulo, Escola Superior de Agricultura Luiz de Queiroz, São Paulo, 2002.

CONFEDERAÇÃO DA AGRICULTURA E PECUÁRIA DO BRASIL (CNA). Balanço 2016 e Perspectivas 2017. Brasília, 2016. Disponível em: <http://www.cnabrasil.org.br/sites/default/files/sites/default/files/uploads/balanco_201 6_perspectivas2017_web.pdf>. Acesso em: 04 jan.2017.

DORNELAS, J. Empreendedorismo: Transformando ideias em negócios. 4. ed. Rio de Janeiro: Elsevier, 2012.

DRUCKER, P. F. Inovação e Espírito Empreendedor: Práticas e Princípios. Tradução de Carlos Malferrari. São Paulo: Cengage Learning, 2012.

EISENHARDT, K.; GRAEBNER, M. Theory Building from Cases: Opportunities and Challenges. Academy of Management Journal, 50(1), 25-32. 2007 
EISENHARDT, K. M. Building Theories from Case Study Research. Academy of Management Review, 14(4), 522-550. 1989.

FAUTH, E. M. Agricultura Familiar: Evolução Favorável em Anos Recentes. Indic. Econ. FEE, Porto Alegre, v. 35, n.4, p. 51-60, jan. 2008.

FERNANDES, A.M.S. O Pronaf na agricultura familiar: sua criação, distribuição e principais resultados. 2013. 58f. Trabalho de Conclusão de Curso (Bacharel em Economia) - Universidade Federal do Rio Grande do Sul, Faculdade de economia e relações internacionais, Porto Alegre, 2013.

FILION, L. J. Diferenças entre sistemas gerenciais de empreendedores e operadores de pequenos negócios. Revista de Administração de Empresas, São Paulo, v.39, n.4, p. 6-20, out./dez.1999b.

FILION, L. J. Empreendedorismo: empreendedores e proprietários-gerentes de pequenos negócios. Revista de Administração. São Paulo, v.34, n.2, p.05-28, abrl./jun.1999a.

FRANÇA, C.G.; DEL GROSSI, M.E.; MARQUES, V.P.M.A. O censo agropecuário 2006 e a agricultura familiar no Brasil. Brasília: MDA, 2009. Disponível em: <http://www.bb.com.br/docs/pub/siteEsp/agro/dwn/CensoAgropecuario.pdf>. Acesso em: 25 out.2016.

INSTITUTO NACIONAL DE COLONIZAÇÃO E REFORMA AGRÁRIA (INCRA). Classificação dos imóveis rurais. 2016. Disponível em: <http://www.incra.gov.br/tamanho-propriedades-rurais>. Acesso em: 05 dez.2016.

JANK, M. S. Agricultura familiar vs agronegócio é uma falácia e um besteirol. Folha de São Paulo, 21/01/2017, Espaço Aberto. Disponível em: <http://www.beefpoint.com.br/cadeia-produtiva/espaco-aberto/agricultura-familiar-vsagronegocioe-uma-falacia-e-um-besteirol-por-marcos-sawaya-jank/>. Acesso em: 05 fev.2017.

KIYOTA, N. Agricultura familiar e suas estratégias de comercialização: um estudo de caso no município de Capanema região sudoeste do Paraná. 1999. 149f. Dissertação (Mestrado em Administração rural) - Universidade Federal de Lavras, Curso de Mestrado em Administração Rural, Minas Gerais, 1999.

LIMA, C.C; PARTELLI, L.F; LOOSE, C.E. O empreendedorismo rural e a agroindústria familiar na gestão da atividade agropecuária em Rondônia. Revista de Administração e Contabilidade, Rondônia, Ano 14, n. 27, p.97-134, jan./jun. 2015.

LIMA, D.A.A. Análise das Barreiras que Impactam a Transformação do Agricultor Familiar em Empreendedor Rural. 2010. 151f. Dissertação (Mestrado em Administração de Empresas) - Pontifícia Universidade Católica do Rio de Janeiro, Departamento de Administração, Rio de Janeiro, 2010.

MAIA, T. S. T.; LIMA, E. APRENDIZAGEM E DECISÃO ESTRATÉGICA REALIZADAS POR EQUIPES DE DIREÇÃO EM PEQUENAS EMPRESAS. REGEPE-Revista de Empreendedorismo e Gestão de Pequenas Empresas, v. 5, n. 3, p. 5989, 2016.

MALDANER, G. C. Contribuição do Pronaf no desenvolvimento da cadeia do leite no município de Pinhalzinho - SC. 2014. 89 f. TCC (Graduação) - Curso de Agronomia, Universidade Federal da Fronteira Sul, Chapecó, 2014.

MILES, M.B.; Huberman, A. M. Qualitative data analysis: an expanded sourcebook. California: Sage. 1994

MINAYO, M. C. Pesquisa Social: Teoria, Método e Criatividade. Petrópolis: Editora Vozes. 2004

MIYAZAKI, J. et al. Capital social e empreendedorismo rural: a agricultura familiar no oeste do Paraná. Unioeste, Paraná, 2008. Disponível em: <http://www.unioeste.br/campi/cascavel/ccsa/IVSeminario/IVSeminario/Artigos/11.pd f>. Acesso em 21 nov.2016.

SECRETARIA DE ESTADO DA AGRICULTURA E DA PESCA. Notícias: Agronegócio movimenta R\$ 61 bilhões na economia catarinense, 2016. Disponível em: <http://www.agricultura.sc.gov.br/index.php/noticias/280agronegociomovimenta-r-61-bilhoes-na-economia-catarinense>. Acesso em: 12 jan.2017.

SECRETARIA ESPECIAL DE AGRICULTURA FAMILIAR E DO DESENVOLVIMENTO AGRÁRIO (SEAD). Notícias: o que é a agricultura familiar. Brasília, 2016. Disponível em: <http://www.mda.gov.br/sitemda/noticias/o-que\%C3\%A9agricultura-familiar $>$. Acesso em: 18 out.2016.

VERGARA, S. C. Projetos e relatórios de pesquisa em administração. 14 ed. São Paulo: Atlas, 2013.

ZYLBERSZTAJN, D.; NEVES, M. F. (Org.). Economia e Gestão dos Negócios Agroalimentares. São Paulo: Pioneira, 2000. 